\title{
PENERAPAN MANAJEMEN PROYEK PADA TAHAP PENGENDALIAN WAKTU PELAKSANAAN PROYEK SOFT LANDSCAPING JUMEIRAH RESORT PECATU GRAHA BALI
}

\author{
Ni Ketut Utami Nilawati ${ }^{1}$, I Gde Eka Dharsika ${ }^{2}$ \\ ${ }^{1}$ Program Studi Teknik Informatika, Fakultas Teknik, STIMIK STIKOM Indonesia, \\ Jl. Tukad Pakerisan Nomor 97 Denpasar, Bali. \\ Email: utaminilawati@gmail.com \\ ${ }^{2}$ Program Studi Teknik Informatika, Fakultas Teknik, STIMIK STIKOM Indonesia, \\ Jl. Tukad Pakerisan Nomor 97 Denpasar, Bali. \\ Email: e.dharsika@gmail.com
}

\begin{abstract}
Abstrak - Jasa konstruksi semakin dibutuhkan dalam pelaksanaan proyek terutama adanya pelayanan jasa yang dapat mengendalikan tuntutan utama mengenai ketepatan kualitas, efisiensi pembiayaan dan keakuratan waktu sangat diperlukan. Dalam pelaksanaan Proyek Pembangunan Jumeirah Resort Pecatu Graha Bali peneliti memfokuskan penelitian pada pekerjaan soft landscaping. Peranan manajemen proyek dalam pengendalian waktu pelaksanaan adalah untuk memperoleh suatu cara atau teknik yang baik untuk diterapkan agar sumber-sumber yang terbatas dapat diatur sehingga memperoleh hasil yang efektif dan efisien karena pengaturan yang tertata dengan baik.

Kurva "S" merupakan salah satu teknik pengendalian kemajuan proyek dengan memakai kombinasi Kurva "S" dan tonggak kemajuan (milestone). Setelah melihat jadwal rencana dan membandingkan dengan progress di lapangan, terdapat keterlambatan pekerjaan yang sangat signifikan pada pekerjaan: (a) Pekerjaan Groundcover, jika dilihat dari time schedule bulan februari 2019 pekerjaan groundcover seharusnya sudah selesai dikerjakan, tetapi data progress di lapangan pada bulan tersebut baru mencapai 30,92\%; (b) Pekerjaan Shrubs, jika dilihat dari time schedule bulan maret 2019 pekerjaan shrubs seharusnya sudah selesai dikerjakan, tetapi data progress di lapangan pada bulan tersebut baru mencapai 35,86\%; (c) Pekerjaan Palms, jika dilihat dari time schedule bulan april 2019 pekerjaan palms seharusnya sudah mencapai tahap akhir pekerjaan, tetapi data progress di lapangan pada bulan tersebut baru mencapai 43,69\%. Faktor-Faktor penyebab keterlambatan pekerjaan berdasarkan laporan harian diantaranya : (a) Belum siapnya lahan untuk penanaman karena masih menunggu pekerjaan sipil selesai; (b) Keterlambatan pasokan tanaman jenis : groundcover, shrubs dan palms, karena tanaman didatangkan dari Pulau Jawa, khususnya daerah malang.
\end{abstract}

Kata kunci: manajemen proyek, waktu pelaksanaan, pengendalian

\begin{abstract}
Construction are increasingly needed in the implementation of projects, especially the existence of services that can control the main demands regarding the accuracy of quality, financial efficiency and time accuracy are very much needed. In implementing the Jumeirah Resort Pecatu Graha Bali Development Project, researchers focused their research on soft landscaping work. The role of project management in controlling the implementation time is to obtain a good way or technique to be applied so that limited resources can be managed so as to obtain effective and efficient results due to well-ordered arrangements.

The "S" curve is one of the techniques for controlling project progress by using a combination of the "S" curve and the milestone. After looking at the schedule of plans and comparing with progress in the field, there are very significant delays in work on: (a) Groundcover work, when viewed from
\end{abstract}


February 2019 time schedule groundcover work should have been completed, but progress data in the field in that month only reached 30.92\%; (b) Shrubs work, if seen from March 2019 time schedule shrubs work should have been completed, but progress data in the field in that month only reached 35.86\%; (c) Palms work, if seen from April 2019 time schedule palms work should have reached the final stage of work, but progress data in the field in that month only reached $43.69 \%$. Factors causing the delay in work based on daily reports include: (a) Land not yet ready for planting because it is still waiting for civil works to be completed; (b) Delay in supply of types of plants: groundcover, shrubs and palms, because plants are imported from Java, especially in Malang areas.

Keywords: project management, time schedule, controlling

\section{Pendahuluan}

Meningkatnya pertumbuhan ekonomi menyebabkan perkembangan pembangunan semakin meningkat. Bali sebagai daerah pariwisata mengalami perkembangan yang cukup pesat dalam pembangunan fasilitas pariwisata terutama pembangunan Hotel dan Resort. Jasa konstruksi semakin dibutuhkan dalam pelaksanaan proyek terutama adanya pelayanan jasa yang dapat mengendalikan tuntutan utama mengenai ketepatan kualitas, efisiensi pembiayaan dan keakuratan waktu sangat diperlukan.

Dalam pelaksanaan Proyek Pembangunan Jumeirah Resort Pecatu Graha Bali peneliti memfokuskan penelitian pada pekerjaan soft landscaping dimana pekerjaan soft landscaping sering mengalami kendala dengan pekerjaan sipil. Pada umumnya pekerjaan soft landscaping baru dapat dimulai jika pekerjaan sipil telah selesai.

Pengendalian waktu pada proyek merupakan hal yang utama dan penting bagi kontraktor. Dalam pelaksanaan proyek waktu pelaksanaan dapat menyimpang dari rencana sehingga harus dikendalikan agar anggaran biaya dan waktu yang telah ditetapkan tidak terlampaui. Keterlambatan penyelesaian pekerjaan dapat menyebabkan bertambahnya biaya bila kontraktor tidak melakukan pemantauan dan pengendalian kegiatan proyek.

Peranan manajemen proyek dalam pengendalian waktu pelaksanaan adalah untuk memperoleh suatu cara atau teknik yang baik untuk diterapkan agar sumber-sumber yang terbatas dapat diatur sehingga memperoleh hasil yang efektif dan efisien karena pengaturan yang tertata dengan baik.

Proyek adalah sebuah kegiatan yang bersifat sementara yang telah ditetapkan awal pekerjaannya dan waktu selesainya. Biasanya selalu dibatasi oleh waktu dan biaya, untuk mencapai tujuan dan hasil yang spesifik dan unik, pada umumnya untuk menghasilkan sebuah perubahan (Santosa, 2009).

Landscape sebagai gabungan antara seni dan ilmu yang berhubungan dengan desain taman dengan menggunakan tanaman hias sebagai komponen utama. Proyek landscape disebut sebagai seni karena berdasarkan pada penerapan prinsip-prinsip desain untuk menciptakan lingkungan yang indah atau memiliki nilai estetika tinggi. Pentingnya perancangan landscape di setiap ruang atau lahan diharapkan menjadi hasil yang lebih baik (Lakitan, 1995).

Arsitektur landscape atau seni taman adalah ilmu yang mempelajari tentang seni, perencanaan, perancangan, manajemen, perawatan, dan perbaikan tanah dan perancangan konstruksi buatan-manusia skala besar (Hakim, 2012). Landscape merupakan suatu bentang alam dengan karakteristik tertentu yang dapat dinikmati oleh seluruh indera manusia, dengan karakter menyatu secara alami dan harmonis untuk memperkuat karakter landscape tersebut. Menurut Suharto (1994) landscape mencakup semua elemen pada tapak, baik elemen alami (natural landscape), elemen buatan (artificial landscape) dan penghuni atau makhluk hidup yang ada di dalamnya. Dapat disimpulkan, pengertian landscape adalah suatu lahan atau tata ruang luar dengan elemen alami dan elemen buatan yang dapat dinikmati oleh indera manusia. 
Manajemen merupakan suatu sistem yang di dalamnya terdapat rangkaian kegiatan yang berkaitan dan tidak dapat dipisahkan antara fungsi satu dengan yang lainnya. Penerapan Manajemen proyek memiliki banyak keuntungan dibandingkan dengan sistem konvensional.

Proses manajemen diperlukan sebagai suatu sistem yang menyeluruh dan terpadu dengan tujuan untuk mencapai hasil yang efisien dalam aspek biaya, mutu dan waktu. Pengendalian merupakan fungsi akhir dari proses manajemen. Dalam setiap pelaksanaan pekerjaan, pengendalian harus selalu dilakukan. Pengendalian adalah usaha yang sistematis untuk menentukan standar agar sesuai dengan sasaran perencanaan, merancang sistem informasi, membandingkan pelaksanaan dengan standar, menganalisis kemungkinan adanya penyimpangan antara pelaksanaan dengan standar dan mengambil tindakan pembetulan yang diperlukan agar sumber daya digunakan secara efektif dan efisien dalam rangka mencapai sasaran (Soeharto, 1997).

Pengendalian yang dilakukan adalah memastikan bahwa segala sesuatunya berjalan sesuai dengan rencana yang ditetapkan, intruksi yang diberikan dan prinsip yang telah ditentukan.

\section{Metodologi}

Kurva "S" adalah sebuah grafik yang dikembangkan oleh Warren T. Hanumm atas dasar pengamatan terhadap sejumlah besar proyek sejak awal hingga akhir proyek. Kurva "S" dapat menunjukkan kemajuan proyek berdasarkan kegiatan, waktu dan bobot pekerjaan yang direpresentasikan sebagai persentase kumulatif dari seluruh kegiatan proyek (Husen, 2010).

Visualisasi Kurva "S" dapat memberikan informasi mengenai kemajuan proyek dengan membandingkan terhadap jadwal rencana. Dari sinilah diketahui apakah ada keterlambatan atau percepatan jadwal proyek. Indikasi tersebut dapat menjadi informasi awal untuk melakukan tindakan koreksi dalam proses pengendalian waktu.
Untuk membuat Kurva "S", jumlah persentase kumulatif bobot masing-masing kegiatan pada suatu periode di antara durasi proyek diplotkan terhadap sumbu vertical sehingga bila hasilnya dihubungkan dengan garis, akan membentuk Kurva "S". Bentuk demikian terjadi karena volume kegiatan pada bagian awal masih sedikit, kemudian pada pertengahan meningkat dalam jumlah cukup besar, lalu pada akhir proyek volume kegiatan kembali mengecil.

Untuk menentukan bobot pekerjaan, pendekatan yang dilakukan dapat berupa perhitungan persentase berdasarkan biaya per item pekerjaan dibagi nilai anggaran, karena satuan biaya dapat dijadikan bentuk persentase sehingga lebih memudahkan dalam perhitungan.

\section{Hasil dan pembahasan}

Kurva "S" dipakai sebagai laporan proyek bulanan, dimana kurva ini dapat dengan jelas menunjukkan kemajuan pekerjaan dalam bentuk yang mudah dipahami.

Cara menggambarkan Kurva " $\mathrm{S}$ " :

1.Menentukan ketergantungan dari masingmasing pekerjaan yang terlibat dalam proyek.

2.Menentukan jadwal dari masing-masing pekerjaan tersebut.

3.Menghitung bobot (persentase) dari masingmasing pekerjaan dengan perbandingan antara biaya masing-masing pekerjaan dengan total biaya

4.Mendistribusikan bobot pekerjaan secara merata, yaitu dengan membagi bobot dengan durasi masing-masing pekerjaan, sehingga diperoleh bobot persatuan waktu.

5.Menjumlahkan bobot pekerjaan yang terdistribusi tersebut secara komulatif untuk setiap satuan waktu, yaitu dari waktu permulaan proyek sampai dengan waktu penyelesaian proyek.

6.Menuliskan nilai hasil penjumlahan tersebut pada bagian bawah diagram batang

7.Plot titik-titik pada diagram batang sesuai dengan nilai hasil penjumlahan untuk masingmasing waktunya

8.Menghubungkan titik-titik yang sudah di plot tersebut maka diperoleh kurva $\mathrm{S}$. meningkat dalam jumlah cukup besar, lalu pada akhir proyek volume kegiatan kembali mengecil. 
Untuk menentukan bobot pekerjaan, pendekatan yang dilakukan dapat berupa perhitungan persentase berdasarkan biaya per item pekerjaan dibagi nilai anggaran, karena satuan biaya dapat dijadikan bentuk persentase sehingga lebih memudahkan dalam perhitungan.

Pada Proyek Soft Landscaping terdapat 11 (sebelas) uraian pekerjaan, yaitu:

1.Preliminaries

2.Large Trees

3.Small Trees

4.Palms

5.Shrubs

6.Ground Cover

7.Vines

8.Grass

9.Water Plant

10.Growing Media

11.Miscellaneous

Kurva "S" Rencana diperoleh dari kontraktor pelaksana yang merupakan jadwal rencana pekerjaan.

Selanjutnya menghitung bobot masing-masing pekerjaan, dengan rumus :

$=$ (harga pekerjaan $/$ harga total pekerjaan $) \mathrm{x}$ $100 \%$

$=$ bobot per pekerjaan.

Langkah berikutnya adalah membagi bobot pekerjaan dengan durasi, kemudian meletakkan pada kolom hari.

Untuk hasilnya ditampilkan seperti pada gambar di bawah ini :

\section{Gambar 1. Kurva "S" Rencana Pekerjaan}

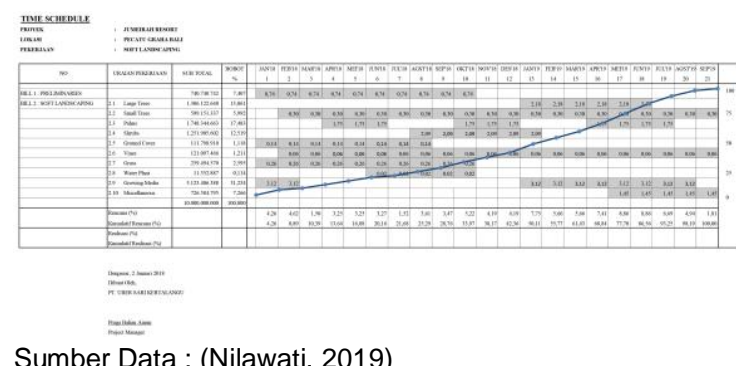

Kurva "S" Realisasi diperoleh dari kontraktor pelaksana yang merupakan jadwal realisasi pekerjaan di lapangan

Gambar 2. Kurva "S" Realisasi Pekerjaan

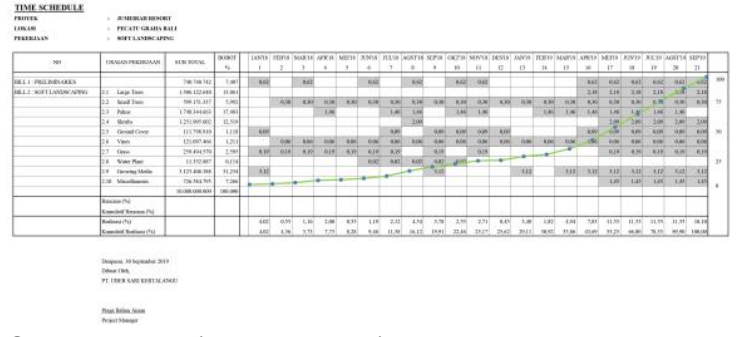

Sumber Data : (Nilawati, 2019)

Dari hasil evaluasi progress pekerjaan pada realisasi pelaksanaan proyek soft landscaping jumeirah resort pecatu graha bali, mengalami keterlambatan dan tidak sesuai dengan rencana. Dalam rencana kerja atau time schedule dapat dilihat grafik realisasi keterlambatan pekerjaan yang dicapai kontraktor.

Berikut adalah grafik keterlambatan pekerjaan yang dapat dilihat menggunakan Kurva "S"

Gambar 3. Kurva "S" Rencana dan Realisasi Pekerjaan

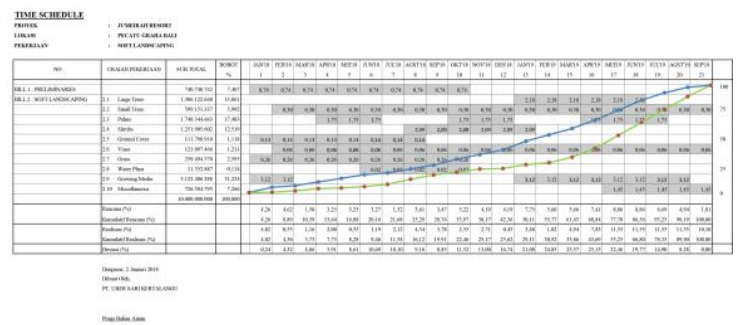

Sumber Data : (Nilawati, 2019)

Setelah melihat jadwal rencana dan membandingkan dengan progress di lapangan, terdapat keterlambatan pekerjaan yang sangat signifikan pada pekerjaan:

1.Pekerjaan Groundcover

Jika dilihat dari time schedule bulan februari 2019 pekerjaan groundcover seharusnya sudah selesai dikerjakan, tetapi data progress di lapangan pada bulan tersebut baru mencapai $30,92 \%$. Hal ini menyimpang dari progress rencana sebesar $24,85 \%$

\section{Pekerjaan Shrubs}

Jika dilihat dari time schedule bulan maret 2019 pekerjaan shrubs seharusnya sudah selesai dikerjakan, tetapi data progress di lapangan pada bulan tersebut baru mencapai $35,86 \%$. 
Hal ini menyimpang dari progress rencana sebesar $25,57 \%$

3.Pekerjaan Palms

Jika dilihat dari time schedule bulan april 2019 pekerjaan palms seharusnya sudah mencapai tahap akhir pekerjaan, tetapi data progress di lapangan pada bulan tersebut baru mencapai $43,69 \%$. Hal ini menyimpang dari progress rencana sebesar $25,15 \%$

\section{Kesimpulan dan Saran}

Dari Pembahasan evaluasi kemajuan proyek soft landscaping jumeirah resort pecatu graha bali dapat disimpulkan bahwa :

a. Adanya perbedaan antara realisasi pelaksanaan di lapangan dengan time schedule, dilihat dari segi waktu yaitu dalam pelaksanaannya mengalami deviasi pekerjaan pada setiap bulannya.

b. Keterlambatan pelaksanaan pekerjaan yang paling signifikan pada bulan februari 2019 sampai dengan bulan april 2019 yaitu pada pekerjaan groundcover, shrubs dan palms

Faktor-Faktor penyebab keterlambatan pekerjaan berdasarkan laporan harian diantaranya :

- Belum siapnya lahan untuk penanaman karena masih menunggu pekerjaan sipil selesai, setelah pekerjaan sipil selesai barulah pekerjaan soft landscaping dapat dikerjakan

- Keterlambatan pasokan tanaman jenis : groundcover, shrubs dan palms, karena tanaman didatangkan dari Pulau Jawa, khususnya daerah malang.

Hal-hal yang dapat disarankan adalah :

1.Pekerjaan soft landscaping yang sering terkendala oleh menunggu waktu penyelesaian pekerjaan sipil, untuk itu perlu perencanaan awal yang lebih matang dibuat dan dilaksanakan di lapangan sehingga dapat mengurangi risiko keterlambatan pekerjaan.

2.Diperlukan pasokan tanaman atau material dari dalam pulau bali, untuk mengantisipasi keterlambatan material dari luar pulau.

\section{Daftar Pustaka}

Asnuddin, S., Tjakra, J., Sibi, M., 2018. "Penerapan Manajemen Konstruksi Pada Tahap Controlling Proyek Bangunan Laboratorium Fakultas Teknik Universitas Sam Ratulangi Manado": Jurnal Sipil Statik Volume 6 (h/m. 895-906). Manado: Universitas Sam Ratulangi.

Hakim, R., Utomo, H., 2012. Komponen Perancangan Arsitektur Lansekap: PrinsipUnsur dan Aplikasi Desain. Jakarta : Bumi Aksara.

Husen, A., 2010. Manajemen Proyek, Perencanaan, Penjadwalan \& Pengendalian Proyek. Jakarta : Andi.

Lakitan, B. 1995. Hortikultura, Teori, Budidaya, dan Pasca Panen. Jakarta : PT Raja Grafindo Persada.

Rabindra. 2009. "Nilai Kearifan Lokal Dalam Penataan Ruang Kota Berkelanjutan, Implementasi Filosofi Trihitakarana di Bali": Jurnal Arsitektur Lansekap Volume 2 No 3 (2009). Jakarta: Universitas Trisakti.

Santosa, B. 2009. Manajemen Proyek Konsep dan Implementasi. Yogyakarta: Graha IImu.

Suharto.1997. Dasar-Dasar Pertamanan Menciptakan Keindahan dan Kerindangan. Jakarta: Media Wiyata. 